\title{
Increased myoepithelial cells of bronchial submucosal glands in fatal asthma
}

\author{
F H Y Green, ${ }^{1}$ D J Williams, ${ }^{1}$ A James, ${ }^{2,3}$ L J McPhee, ${ }^{1}$ I Mitchell, ${ }^{1}$ T Mauad $^{4}$
}

\begin{abstract}
- Additional data are published online only at http://thorax.bmj. com/content/vol65/issue1

${ }^{1}$ Respiratory Research Group, Faculty of Medicine, University of Calgary, Alberta, Canada;

${ }^{2}$ Department of Pulmonary Physiology, West Australian Sleep Disorders Research Institute, Queen Elizabeth II Medical Centre, Perth, Western Australia, Australia; ${ }^{3}$ School of Medicine and Pharmacology, University of Western Australia, Perth, Western Australia, Australia; ${ }^{4}$ Laboratory of Air Pollution, Department of Pathology, Sao Paulo University Medical School, Sao Paulo, SP, Brazil
\end{abstract}

Correspondence to:

Dr F H Y Green, Pathology and Laboratory Medicine, Faculty of Medicine, University of Calgary, 3330 Hospital Drive NW, Calgary, Alberta T2N 4N1.

Canada; fgreen@ucalgary.ca

Received 11 December 2008 Accepted 18 October 2009 Published Online First

8 December 2009

\section{ABSTRACT}

Background: Fatal asthma is characterised by enlargement of bronchial mucous glands and tenacious plugs of mucus in the airway lumen. Myoepithelial cells, located within the mucous glands, contain contractile proteins which provide structural support to mucous cells and actively facilitate glandular secretion.

Objectives: To determine if myoepithelial cells are increased in the bronchial submucosal glands of patients with fatal asthma.

Methods: Autopsied lungs from 12 patients with fatal asthma (FA), 12 patients with asthma dying of nonrespiratory causes (NFA) and 12 non-asthma control cases (NAC) were obtained through the Prairie Provinces Asthma Study. Transverse sections of segmental bronchi from three lobes were stained for mucus and smooth muscle actin and the area fractions of mucous plugs, mucous glands and myoepithelial cells determined by point counting. The fine structure of the myoepithelial cells was examined by electron microscopy.

Results: FA was characterised by significant increases in mucous gland $(p=0.003)$, mucous plug $(p=0.004)$ and myoepithelial cell areas $(p=0.017)$ compared with NAC. When the ratio of myoepithelial cell area to total gland area was examined, there was a disproportionate and significant increase in FA compared with NAC $(p=0.014)$. Electron microscopy of FA cases revealed hypertrophy of the myoepithelial cells with increased intracellular myofilaments. The NFA group showed changes in these features that were intermediate between the FA and NAC groups but the differences were not significant.

Conclusions: Bronchial mucous glands and mucous gland myoepithelial cell smooth muscle actin are increased in fatal asthma and may contribute to asphyxia due to mucous plugging.

The World Health Organization estimates that 255000 people died of asthma in 2005 and that 300 million people are currently affected by asthma. ${ }^{1}$ Death occurs by asphyxiation owing to airway closure through bronchoconstriction and mucous plugging on a background of inflammation and airway wall remodelling. ${ }^{2-4}$ Research has focused more on the changes in airway smooth muscle and less on the enlarged mucous glands and tenacious mucous plugs. ${ }^{35-7}$ Overproduction of mucus in patients with asthma stems from a combination of hyperplasia of goblet cells and enlargement of the bronchial submucosal glands. ${ }^{5}$ The mucus in asthma has altered viscoelastic and biochemical properties that contribute to adhesivity and impaired clearance. ${ }^{89} \mathrm{In}$ asthma there is an increase in the ratio of mucous to serous cells within the mucous glands. ${ }^{5}$ Mucus produced in the glands is secreted into the mucous gland ducts and from there expelled into the airway lumen.

Myoepithelial cells are ubiquitous components of exocrine glands. They lie between the basement membrane and the basal surface of the acinar cells and have "octopus-like" branching processes which extend between the secretory epithelial cells. ${ }^{10}$ They have been studied in the salivary, mammary, prostate, lachrymal and sweat glands in several species. ${ }^{10-12}$ Meyrick and Reid $^{13}$ described the anatomical features of myoepithelial cells beneath the serous, mucous and collecting duct cells of human bronchial submucosal glands. However, the mechanism of mucus expulsion from the glandular acini has not been studied in human bronchial mucous glands.

Myoepithelial cells are contractile in nature, possessing myofilaments composed of actin and myosin. ${ }^{101314}$ Their contraction contributes to glandular secretion. ${ }^{14}$ The mechanism of stimulation varies by gland type and species. Contraction may be caused by cholinergic, adrenergic or nonadrenergic/non-cholinergic mechanisms. ${ }^{15}$

As the area of the submucosal glands is increased in fatal asthma, ${ }^{35-7}$ it is reasonable to assume that the myoepithelial cell network is also increased in relation to the increase in gland size. Given the striking amount of mucus found at autopsy in the airways in status asthmaticus and the marked increase in airway smooth muscle, ${ }^{47}$ we hypothesised that contractile elements are disproportionately increased within the mucous glands in fatal asthma. We report that this is the case-a finding that has important implications for understanding and preventing death from asthma.

\section{METHODS}

\section{Subjects and study design}

The study was based on autopsy materials collected for the Prairie Provinces Asthma Study (PPAS), a multicentre study of asthma fatalities occurring in Alberta, Saskatchewan and Manitoba from November 1992 to October 1995. ${ }^{16}$ Cases were defined as subjects dying of asthma (fatal asthma, FA). There were two control groups: a non-fatal asthma (NFA) group comprising subjects with a history of asthma but who had died of nonrespiratory causes and a non-asthma control (NAC) group with no history of asthma or other respiratory disease at death. Deaths occurring in individuals with a history of asthma were reported to the study team through the medical examiners or coroner's offices, hospitals and provincial vital statistics departments. Provincial departments of vital statistics were contacted every 3 months to ensure that no deaths classified as asthma in this 
age range were missed. NAC cases were obtained from the Alberta Medical Examiner's Office and local hospitals. The criteria used by the pathologists and clinicians to classify the cases and control subjects, as well as the inclusion/exclusion criteria, are available in the online supplement.

After notification of death, the study team contacted the next of kin to obtain consent for autopsy. The next of kin were asked to complete a questionnaire that sought information on asthma severity, age of onset, duration of asthma, asthma medications and smoking history. Those with a history of asthma were assigned a category for asthma severity, unrelated to the cause of death, based on 2006 guidelines from the Global Initiative for Asthma. ${ }^{17}$ Subjects were classified as having severe asthma if they were using oral corticosteroids, reported hospitalisations for asthma (ever) or had daily symptoms. Subjects who had none of the above but had symptoms on most days or nights (more than 3 days per week), used regular inhaled corticosteroids or used reliever medications on most days or nights were classified as having moderate asthma. All other cases were classified as mild.

\section{Tissue sampling for light microscopy and morphometry}

Left lungs taken at autopsy were fixed in inflation via the blood vessels and airways with glutaraldehyde fixative $(2.5 \%$ in $0.1 \mathrm{M}$ phosphate buffer, $\mathrm{pH}$ 7.3). The airway pressure was $20 \mathrm{~cm} \mathrm{H}_{2} \mathrm{O}$. The dual fixation method was developed to circumvent the poor airway perfusion resulting from mucous plugs in the FA group. Transverse sections from segmental bronchi were used from three sites: left upper lobe (LUL), left lower lobe anterior bronchus (LAB) and left lower lobe posterior bronchus (LPB). Segmental bronchi were selected because they contained the greatest proportion of mucous glands relative to airway wall size. Tissue blocks were embedded in paraffin wax and sections stained with haematoxylin and eosin (H\&E) and Alcian blue/PAS (AB/PAS) at $\mathrm{pH} 2.5$ for characterisation of mucous plugs and mucous cells. Sections from the LPB were immunostained for smooth muscle actin (DAKO Immunostain) for identification of myoepithelial cells. More detail of the fixation techniques and sampling sites are available in the online supplement.

\section{Morphometry}

The area fractions of components of the airway wall and mucous glands were determined by point counting using a Zeiss-Axioplan light microscope, drawing tube and square lattice grid containing 240 points. ${ }^{18}$

Structures identified and quantified by area on the H\&E stained sections of the whole bronchus included bronchial mucous glands and the bronchial airway lumen (subdivided into free lumen and mucus/cells). The perimeter of the airway (Pbm) was determined on the same grid by counting the number of intersections between the grid lines and the luminal aspect of the epithelial basement membrane (laminar reticularis). ${ }^{4}$ To normalise the mucous gland area to airway size, the mucous gland area was divided by the $\mathrm{Pbm}$. The area of the airway lumen occupied by mucous plugs was calculated by dividing the mucous plug area by the measured total airway luminal area and expressed as a percentage. Mucous gland duct ectasia was graded on the H\&E stained sections on a 5-point scale (0-5) of increasing severity.

Subcomponents of the mucous glands were measured on the sections stained for alpha smooth muscle actin. These included myoepithelial cells, acinar cells (nuclei and cytoplasm), acinar lumen, interstitium and blood vessels. These area fractions were estimated as the number of points falling on the feature of interest divided by the total number of points falling on the mucous gland.

Further details of the morphometric methods are given in the online supplement.

\section{Electron microscopy}

Tissue for ultrastructural analysis was obtained from four subjects who had died of asthma (FA) and underwent autopsy at the Department of Pathology, São Paulo University between 2005 and 2007. All had a history of asthma and no other lung disease. Clinical data including treatment, smoking habits, duration of disease and previous hospitalisations were obtained by administering a questionnaire to the relatives. ${ }^{19}$ Three control subjects were studied, all non-smokers with no history of asthma, wheeze, use of asthma medications or other lung disease and no gross or microscopic evidence of asthma at autopsy.

Small $(2 \times 2 \times 2 \mathrm{~mm})$ fragments of lobar bronchial wall were fixed in $2 \%$ glutaraldehyde dissolved in $0.15 \mathrm{M}$ phosphate buffer at $\mathrm{pH} 7.2$ for $1 \mathrm{~h}$, followed by post-fixation in $1 \%$ osmium tetroxide dissolved in $0.9 \%$ sodium chloride for $1 \mathrm{~h}$ and embedded in Araldite resin. Ultrathin sections were studied with a transmission electron microscope.

\section{Statistical analysis}

A total of 108 cases and controls had been accessioned to the PPAS. A subset of 36 cases (12 FA, 12 NFA, 12 NAC) was used in this study. This sample size was based on preliminary data for airway smooth muscle which revealed that 12 cases per group would provide sufficient power $(77 \%)$ to detect a significant effect. Further information regarding the power calculation is available in the online supplement. From the 108 subjects we randomly selected 12 subjects per group such that each group had equal numbers of men and women, and smokers and nonsmokers. For example, the FA group had six men ( 3 smokers and 3 non-smokers) and six women ( 3 smokers and 3 non-smokers). This selection was done to provide balanced groups to test the relationship between the primary variable of interest, myoepithelial cell size, and asthma group (severity). A comparison of the subgroup of 36 cases in this study with the total population $(n=108)$ showed no significant differences between the two groups for the demographic variables of age, time from death to autopsy, age at onset of asthma, asthma duration and (for smokers) pack years.

For group comparisons (FA, NFA, and NAC), normality assumptions were tested and the appropriate parametric and non-parametric tests were used accordingly. For comparison between groups, one-way ANOVA with post hoc TukeyKramer multiple comparison or Student $t$ tests were used for continuous variables. Pearson $\chi^{2}$ and Fisher exact tests were used for categorical data. A p value of 0.05 or less was considered significant.

\section{RESULTS}

\section{Patient characterisation}

The demographic characteristics and the causes of death of the PPAS study groups are shown in table 1. No significant differences were observed between the FA and NFA groups for age at death, duration of asthma or age at onset of asthma. Asthma severity was significantly greater in the FA group than in the NFA group ( $p=0.032$, Pearson $\chi^{2}$ test). This was reflected 
in the increased use of oral corticosteroids or short-acting bronchodilators in the FA group compared with the NFA group (table 1). Inhaled corticosteroid use was similar for the FA and NFA groups. For those subjects who smoked, the NFA group had significantly $(p=0.04)$ greater pack years than the FA group. The mean time between death and autopsy for the three groups was not significantly different (table 1).

The demographic information for the subjects used for electron microscopy from Sao Paulo, Brazil is summarised in table 2 .

\section{Histology}

The subjects with asthma had increased airway smooth muscle, mucous gland enlargement, mucous duct ectasia, goblet cell hyperplasia of the lining epithelium, thickening of the subepithelial collagen layer and infiltration of eosinophils and lymphocytes in the bronchial wall. In addition, most of the FA cases had extensive mucous plugs and bronchoconstriction. NAC cases had no features of asthma.

Sections stained for smooth muscle actin showed staining of bronchial smooth muscle, vessels and myoepithelial cells of the bronchial mucous glands (fig 1). The latter were located between the basal surface of the glandular epithelial cells (mucous and serous) and the adjacent basement membrane. Fine cytoplasmic processes were seen to extend between the epithelial cells. Myoepithelial cells were only seen in the acini and proximal collecting ducts. They were absent from larger ducts that communicated with the bronchial lumen. In the NAC group the myoepithelial cells appeared to be discontinuous (fig 1B) whereas in the FA group they appeared continuous, thicker and showed patchy layering (fig 1D). The changes in myoepithelial cells from the NFA group were similar to those seen in the FA group but were less pronounced.

\section{Electron microscopy}

In the FA and NAC cases, myoepithelial cells were positioned between the epithelial cells and the basement membrane of the submucosal glands; the latter was thickened in the acini of the subjects with asthma. The myoepithelial cell cytoplasm contained dense bodies and myofilaments which lay parallel to the long axis of the cell. The nuclei were oval or elongated. The myoepithelial cells were attached to the acinar gland cells with desmosomes. In FA the myoepithelial cells had more myofilaments and more prominent cytoplasmic processes extending between the mucous cells (figs 2 and 3). These changes were not quantified.

\section{Morphometry}

Airway size $(\mathrm{Pbm})$ did not differ significantly between the three groups (table 3$)$. Mucous gland area was increased $(p=0.003)$ in the FA group compared with the NAC group when data from all three lobes were included in the analysis.

The average normalised values of subcomponents of the mucous glands were increased in the FA group compared with NFA and NAC (table 4). However, only myoepithelial actin in the FA group was significantly increased $(p=0.017)$ compared with the NAC group. When the ratio of myoepithelial cell area to total gland area was examined, there was a disproportionate and significant $(p=0.014)$ increase for FA compared with the NAC group (table 3 ). The NFA group showed changes in mucous gland area and in the components of the gland that were intermediate between the FA and NAC groups. None of these differences were significant. No significant association between smoking status and myoepithelial actin was found among the groups. Both smoking and non-smoking patients with asthma had equivalent increases in myoepithelial cell area.

In the FA group, $31 \%$ of the airway lumen was occupied by mucus which was significantly greater $(p=0.004)$ than the area

Table 1 Demographic characteristics of the study population on which lung tissue was used for morphometric analysis

\begin{tabular}{|c|c|c|c|}
\hline & $F A(n=12)$ & NFA ( $n=12)$ & NAC (n=12) \\
\hline $\operatorname{Sex}(M / F)^{*}$ & $6 / 6$ & $6 / 6$ & $6 / 6$ \\
\hline Age (years) $\dagger$ & $36(21-51)$ & $35(18-55)$ & $37(19-58)$ \\
\hline Smoking $(\mathrm{S} / \mathrm{NS})^{*}$ & $6 / 6$ & $6 / 6$ & $6 / 6$ \\
\hline Pack years: & $2.5-14$ & $1.25-47.5$ & $9-41.25$ \\
\hline Age at asthma onset (years) $\dagger$ & $11(1-44)$ & $17(2-30)$ & N/A \\
\hline Duration of asthma (years) $\dagger$ & $25(2-43)$ & $19(2-31)$ & $\mathrm{N} / \mathrm{A}$ \\
\hline Asthma severity score§ & $0 / 1 / 11$ & 1/6/4 (1 unknown) & $\mathrm{N} / \mathrm{A}$ \\
\hline Oral corticosteroid & 2/4/5 (1 unknown) & 10/1/0 (1 unknown) & $\mathrm{N} / \mathrm{A}$ \\
\hline Inhaled corticosteroid & 3/5/3 (1 unknown) & $7 / 2 / 3$ & $\mathrm{~N} / \mathrm{A}$ \\
\hline Short-acting bronchodilator & $0 / 1 / 11$ & $3 / 5 / 4$ & $\mathrm{~N} / \mathrm{A}$ \\
\hline Time from death to autopsy** & $26.3(5.0-67.5)$ & $26.6(3.0-58.0)$ & $30.7(7.0-115.5)$ \\
\hline \multirow[t]{9}{*}{ Cause of death } & Asthma & Heart disease: 5 & Drug overdose: 1 \\
\hline & & Asphyxia: 1 & Heart disease: 3 \\
\hline & & Substance abuse: 3 & Brain tumour: 2 \\
\hline & & Morbid obesity: 2 & Cerebral aneurysm: 1 \\
\hline & & Diabetes: 1 & Musculoskeletal: 1 \\
\hline & & & Seizure disorder: 1 \\
\hline & & & Suicide: 1 \\
\hline & & & Meningitis: 1 \\
\hline & & & Malignant melanoma: 1 \\
\hline
\end{tabular}

\footnotetext{
*Data expressed as number of patients.

$\dagger$ Data expressed as median (range).

\$Data expressed as range.

$\S$ Number of patients: mild/moderate/severe.

- Number of patients: none/occasional/everyday use.

**Data expressed in hours as mean (range).

FA, fatal asthma; N/A, not applicable; NFA, non-fatal asthma; NAC, non-asthma control ; NS, non-smoker; S, smoker.
} 
Table 2 Demographic characteristics of subjects from Sao Paulo on which lung tissue was used for ultrastructural analysis

\begin{tabular}{|c|c|c|}
\hline & FA $(n=4)$ & NAC $(n=3)$ \\
\hline $\operatorname{Sex}(M / F)^{*}$ & $3 / 1$ & $0 / 3$ \\
\hline Age (years) $\dagger$ & $48(20-51)$ & $50(46-51)$ \\
\hline Smoking $(\mathrm{S} / \mathrm{NS})^{*}$ & $2 / 2$ & $0 / 3$ \\
\hline Age of asthma onset (years) $\dagger$ & $4(1-10)$, unknown & $\mathrm{N} / \mathrm{A}$ \\
\hline Duration of asthma (years) $\dagger$ & $\begin{array}{l}40 \text { (10-47), } \\
1 \text { unknown }\end{array}$ & $\mathrm{N} / \mathrm{A}$ \\
\hline Time from death to autopsy: & $12(6-15)$ & $9.3(5-14)$ \\
\hline Oral corticosteroid§ & $0 / 4 / 0$ & $\mathrm{~N} / \mathrm{A}$ \\
\hline Inhaled corticosteroid§ & $0 / 2 / 2$ & $\mathrm{~N} / \mathrm{A}$ \\
\hline Short-acting bronchodilator§ & $0 / 1 / 3$ & $\mathrm{~N} / \mathrm{A}$ \\
\hline Cause of death & Asthma & Heart disease \\
\hline
\end{tabular}

*Data expressed as number of patients.

$\dagger$ Data expressed as median (range).

D. Data expressed in hours as mean (range)

$\S$ Number of patients: none/occasional/everyday use.

FA, fatal asthma; N/A, not applicable; NAC, non-asthma controls; NS, non-smoker; S, smoker.

of airway occupied by mucous plugs in the NAC group $(6.9 \%)$ but not the NFA group (15.3\%, $p=0.068$; table 3$)$. The grade of mucous gland duct ectasia was significantly greater $(p=0.012)$ in the FA group compared with the NAC group. There was no significant effect of smoking status on mucous gland size or mucous plug area among the groups.

\section{DISCUSSION}

In this study we show that the increased size of bronchial mucous glands in fatal asthma is accompanied by a disproportionate increase in smooth muscle actin in the myoepithelial cells of the glandular acini. These changes were associated with mucous plugs within the airway lumen and ectasia of the gland ducts. Our results suggest that myoepithelial cells contribute to the abundant mucus that is characteristic of fatal asthma.

The cause(s) of the disproportionate increase in myoepithelial cell area in fatal asthma are unknown. However, two plausible explanations may be postulated. First, it could be due to an increased workload required to expel the highly viscous mucus characteristic of fatal asthma ${ }^{620}$ into the airway lumen. Increased intraduct pressures might also contribute to the mucous gland duct ectasia described in this and other studies. ${ }^{21}$ Second, it may reflect an increased stimulus for mucus secretion in asthma in response to asthma triggers. In this regard, it would be one more component of the airway wall affected by remodelling. The area of the airway smooth muscle layer is also increased in asthma ${ }^{42}$ so that a generalised effect of inflammation, release of growth factors or mechanical influences could affect the amount of contractile tissue within the airway wall, including myoepithelial cells.

We assessed the area fraction of myoepithelial cells based on staining of smooth muscle actin. This gives an estimate of the overall area of myoepithelial cells and, since the thickness of the section is $<10 \%$ of the thickness of the myoepithelial cell, the area fraction provides a good estimate of the volume fraction of these cells. The increased area and volume fraction of actin staining suggests an increase in contractile tissue. The twodimensional approach used in this study did not allow us accurately to estimate the number or size of individual myoepithelial cells and thus we were not able to determine if the changes to the myoepithelial cells resulted from cell hyperplasia and/or hypertrophy. This awaits a separate study.

There are few studies of myoepithelial cells in bronchial mucous glands in humans in the literature. ${ }^{13}$ To our knowledge, this is the first study to examine myoepithelial cells in bronchial mucous glands of patients with asthma. Myoepithelial cells are contractile in nature, possessing myofilaments composed of
Figure 1 (A) Low power $(\times 100)$ photomicrograph of a bronchial mucous gland from an 18-year-old non-smoking, non-asthmatic female. The section is stained for smooth muscle actin and shows staining of myoepithelial cells on the outer border of the mucous gland acini. More intense smooth muscle actin staining is seen of small blood vessels (BV) within and adjacent to the gland. (B) Higher power $(\times 400)$ view of bronchial mucous gland shown in $(A)$. The myoepithelial cell network (arrows) in the normal acinus appears discontinuous. (C) Low power $(\times 100)$ photomicrograph of a mucous gland in the bronchial wall of a 42-year-old non-smoking man who died of asthma. The gland is larger than that seen in the non-asthma control $(A)$. The section is stained for smooth muscle actin. There is marked staining of myoepithelial cells within the mucous gland. (D) Higher power $(\times 400)$ view of centre of gland shown in (C). There is increased staining of myoepithelial cells around the acini. The myoepithelial cells are thicker than in the control $(B)$ and are continuous around the circumference of the acini and in some areas appear multilayered (arrows).
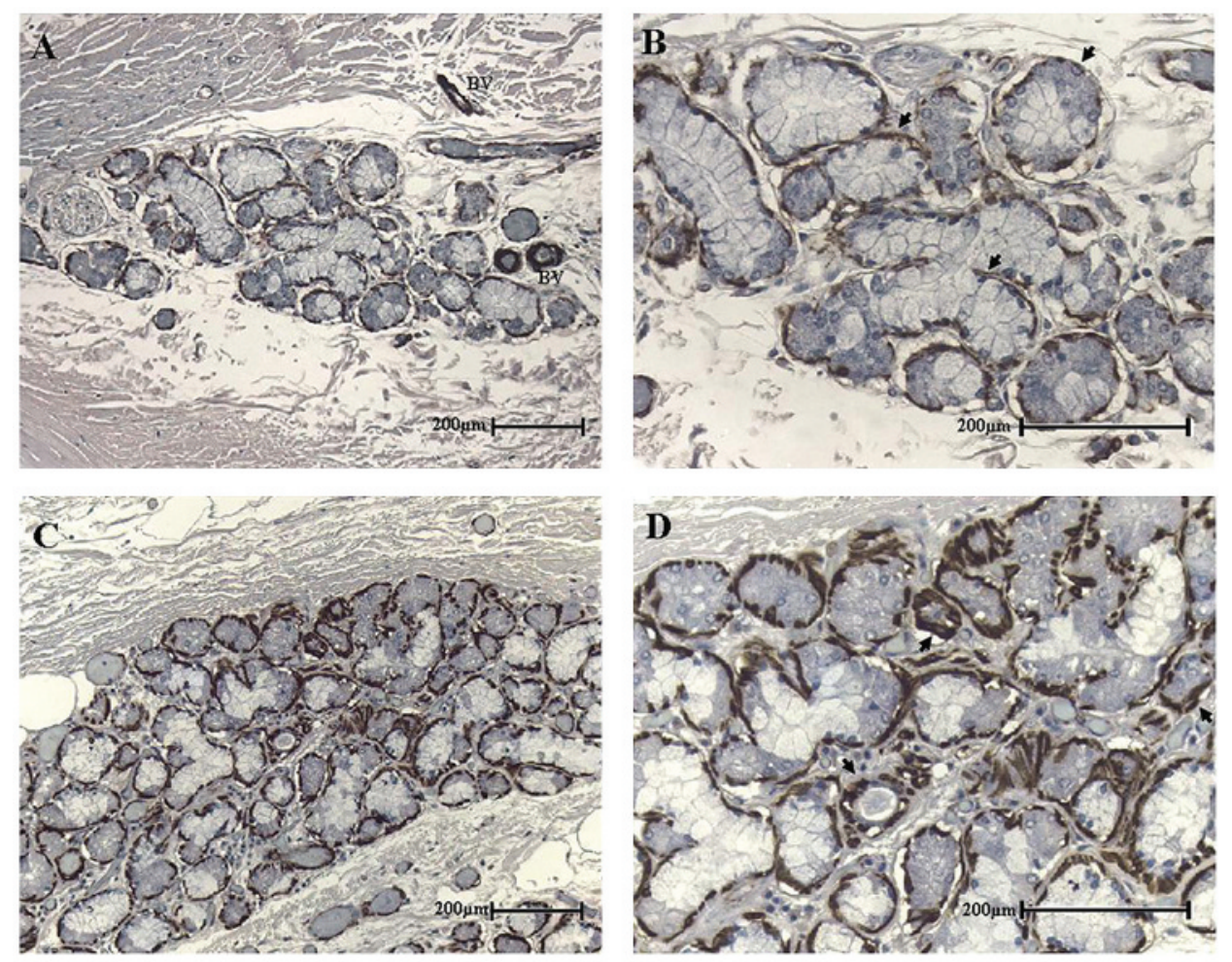

$200 \mu$ 
Figure 2 Ultrastructural aspect of a submucosal gland in a non-smoking nonasthmatic control female patient aged 50 years. (A, B) Myoepithelial cells (mep) lie under the glandular cells $(\mathrm{gc})$ inside the basal lamina (bl). (C) The cytoplasm of the myoepithelial cell has a filamentous appearance (due to the presence of actin and myosin) with dense bodies (arrowheads). The myoepithelial cell is attached to an acinar glandular cell via desmosomes (arrow).
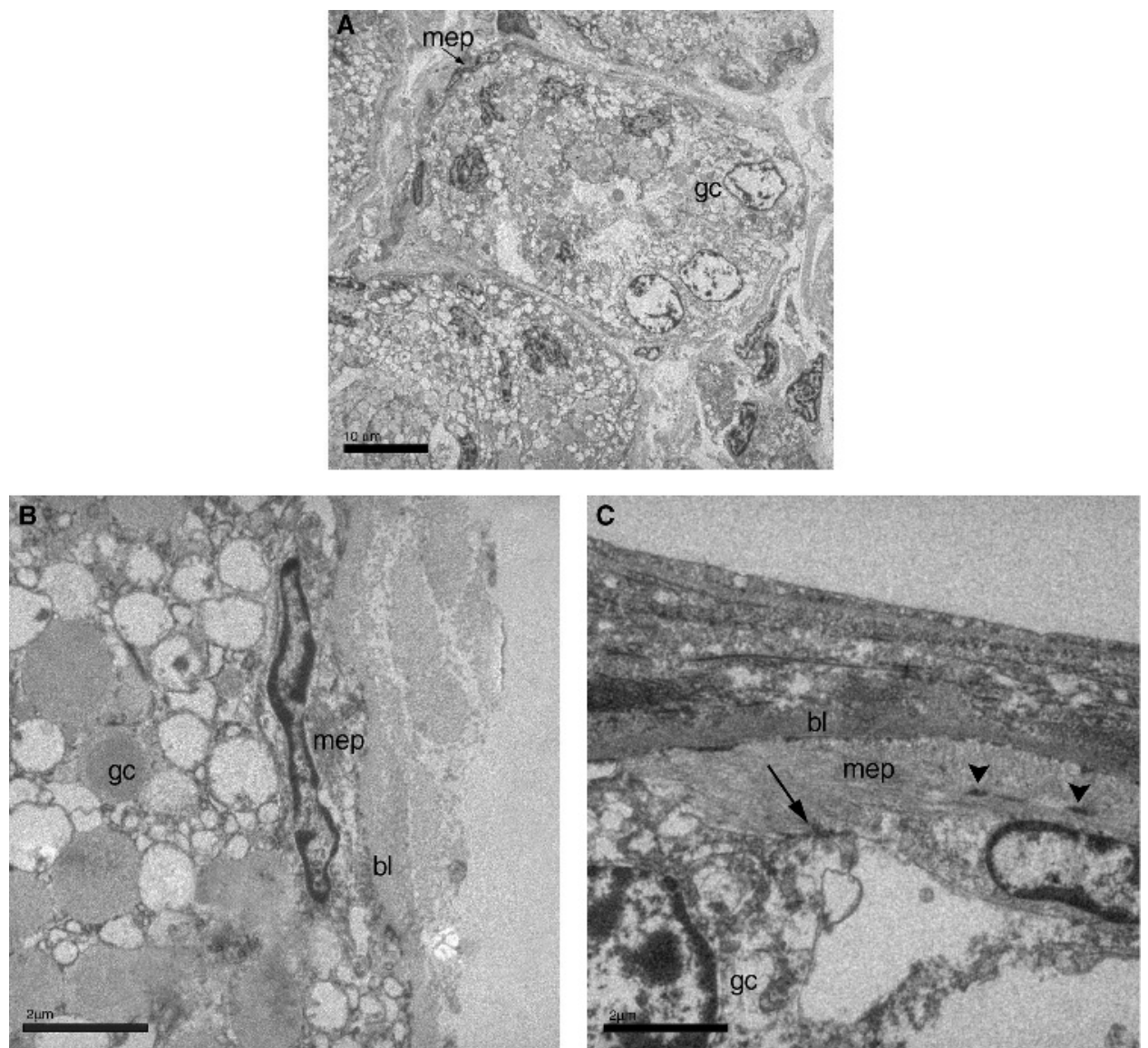

actin and myosin, dense bodies, caveolae and elongated mitochondria. ${ }^{13} 1423$ The mechanism of stimulation varies by gland type and species. For example, myoepithelial cells from human apocrine sweat glands respond to $\alpha$-adrenergic stimulation $^{24}$ whereas porcine bronchial submucosal glands contract in response to acetylcholine. ${ }^{25}$ In dogs, secretion from mucous-type epithelial cells occurs in response to both $\beta$-adrenergic and cholinergic stimulation. ${ }^{15}$ In humans, tachykinin mechanisms may also be important. ${ }^{26}{ }^{27}$ Thus, myoepithelial cell contraction may be caused by cholinergic, $\beta$-adrenergic or peptidergic mechanisms.

Our findings may be relevant to studies of smooth muscle cell function in asthma. Mast cells and neutrophils are increased in the submucosal glands of patients with asthma. ${ }^{28}$ The differentiation and function of myofibroblasts is regulated by mast cell mediators. ${ }^{29}$ Muscarinic receptors, especially the M3 receptor subtype, have been implicated in smooth muscle proliferation $^{30}$ and contractile protein expression in mesenchymal cells in asthma. ${ }^{31}$ Whether similar pathogenetic pathways occur in the myoepithelial cells of the bronchial submucosal glands of patients with asthma is not known, but further research on these topics is warranted.

An increase in bronchial submucosal gland area has been reported as a pathological marker of asthma. ${ }^{5}$ Our study supports this observation. We found a significant increase in mucous gland area as a proportion of airway size in fatal asthma compared with non-asthma controls. Deposition of mucus into the airway lumen is also a prominent feature of fatal asthma, where it is thought to contribute to increased airway resistance $^{32}$ and is readily apparent at autopsy in cases of fatal
Figure 3 Ultrastructural aspect of a submucosal gland in a 45-year-old male smoker with fatal asthma. (A) Myoepithelial cell (mep) with large cytoplasmic branches around the acinar glandular cells $(\mathrm{gc})$. The glandular basal lamina seems to be thickened (bl). (B) Detail of a myoepithelial cell with prominent cytoplasm, rich in myofilaments and showing dense bodies (arrowheads).
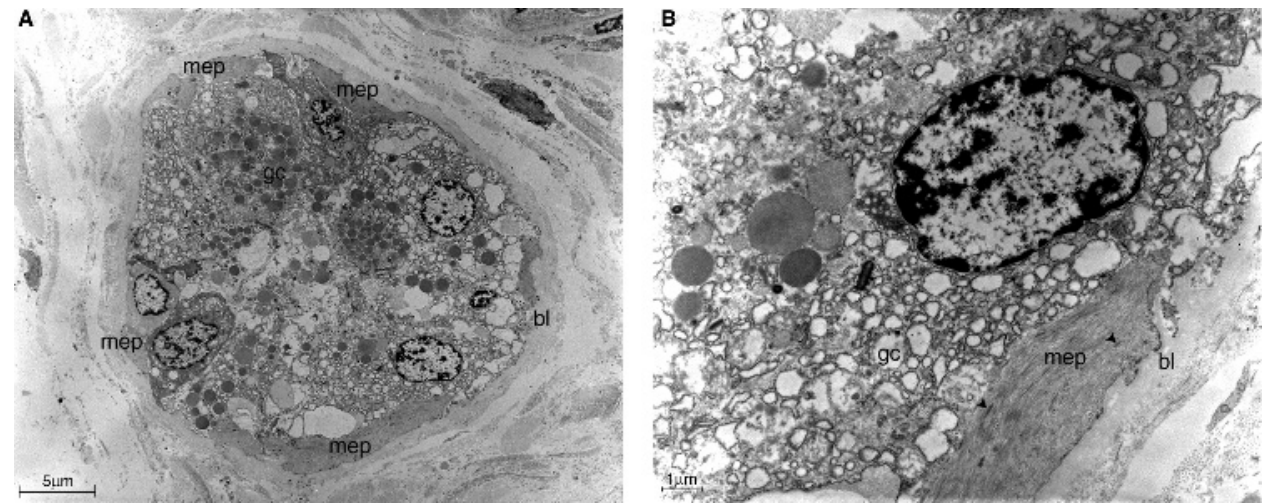
Table 3 Morphometry of selected airway features in fatal asthma (FA) and non-fatal asthma (NFA) cases and non-asthma control (NAC) subjects

\begin{tabular}{|c|c|c|c|c|}
\hline Morphometric parameter & NAC $(n=12)$ & NFA $(n=12)$ & $\mathrm{FA}(\mathrm{n}=12)$ & p Value \\
\hline Airway perimeter, $\mathrm{Pbm}$ (mm) & $16.6(1.2)^{*}$ & $15.6(1.1)$ & $17.1(1.7)$ & $0.954 \dagger$ \\
\hline Total mucous gland areat & $128.6(17.3)$ & $195.4(28.3)$ & $226.6(44.4)$ & $0.003 \dagger$ \\
\hline Mucous plug area/total luminal area§ & $6.9(3.2)$ & $15.3(2.9)$ & $31.0(7.5)$ & $0.004 \uparrow$ \\
\hline $\begin{array}{l}\text { Myoepithelial cell area/mucous gland } \\
\text { area§ }\end{array}$ & $10.9(0.7)$ & $12.2(0.9)$ & $14.5(0.9)$ & $0.014 \dagger$ \\
\hline Grade of mucous gland duct ectasia & $4(33 \%)$ & $6(50 \%)$ & $11(92 \%)$ & $0.012^{* *}$ \\
\hline
\end{tabular}

\footnotetext{
*Values expressed as mean (SEM).

tp Value for FA group compared with NAC group using ANOVA.

tThese areas were normalised to the basement membrane perimeter $(A / \mathrm{Pbm})$.

$\S$ Expressed as a percentage.

-Data expressed as number of patients with grade 2 or greater (percentage of patients).

${ }^{* *}$ p Value for FA group compared with NAC group using Pearson $\chi^{2}$ test.
}

Table 4 Morphometry of selected airway mucous gland subcomponents in fatal asthma (FA) and non-fatal asthma (NFA) cases and non-asthma control (NAC) subjects

\begin{tabular}{lcccc}
\hline Mucous gland subcomponents $\dagger$ & NAC $(\mathbf{n}=\mathbf{1 2})$ & NFA (n= 12) & FA (n= 12) & p Value \\
\hline Actin: myoepithelial & $14.2(2.3)^{*}$ & $22.1(2.7)$ & $32.7(6.9)$ & $0.017 \ddagger$ \\
Actin: non-myoepithelial§ & $2.8(0.5)$ & $3.3(0.4)$ & $3.3(0.4)$ & $0.736 \ddagger$ \\
Acinar cell cytoplasm & $41.0(5.4)$ & $63.8(11.1)$ & $71.9(15.4)$ & $0.151 \ddagger$ \\
Acinar cell nuclei & $4.5(0.6)$ & $8.7(1.5)$ & $9.0(2.3)$ & $0.147 \ddagger$ \\
Acinar lumen & $0.6(0.1)$ & $0.9(0.3)$ & $2.0(0.8)$ & $0.118 \ddagger$ \\
Interstitium & $66.1(9.1)$ & $97.5(14.2)$ & $109.8(20.2)$ & $0.120 \ddagger$ \\
\hline
\end{tabular}

\footnotetext{
*Values expressed as mean (SEM).

$\dagger$ Expressed as area/basement membrane perimeter (A/Pbm).

tp Value for FA group compared with NAC group using ANOVA.

§lncludes arteries, arterioles, veins and lymphatics.

ๆIncludes connective tissue, nerves and inflammatory cells.
}

asthma. ${ }^{67}$ Our study found that luminal mucus content was increased in both NFA and FA groups compared with the NAC group. The FA cases had, on average, $30 \%$ of their airway lumen occupied by mucus compared with approximately $7 \%$ in the NAC group. Similar findings have been reported by other investigators. $^{728}$

Smoking is also associated with an increase in the size of mucous glands in the conducting airways. ${ }^{33}$ Smoking evokes a reflex increase in tracheal submucosal gland secretion in dogs. ${ }^{34}$ The effect of smoking on myoepithelial cells is largely unknown, but myoepithelial cell ultrastructure was reported to be unaffected by smoke exposure in rat tracheal submucosal glands. ${ }^{35}$ In the present study, cigarette smoking was not associated with an increase in myoepithelial cell smooth muscle actin. Our failure to detect an effect of cigarette smoking on myoepithelial cell actin may be related to small sample sizes, the relatively young age of the population and/or the low to moderate pack years of the cigarette smokers.

In summary, we show that excess luminal mucus in fatal asthma is associated with enlarged submucosal glands, increased myoepithelial cell area and a disproportionate increase in myoepithelial smooth muscle actin. These findings add to our understanding of the complex mechanisms leading to death during an acute asthma attack. The results of this study indicate that new therapeutic strategies for asthma treatment might include medications designed to reduce myoepithelial cell contractility.

Acknowledgements: The authors greatly appreciate the time and commitment of the families of the deceased who consented to participate in the study as well as the coroners, medical examiners and healthcare workers from the provinces of Alberta, Saskatchewan and Manitoba. Without their involvement this study would not have been possible. We appreciate the work of Dr Karen Osiowy and Dr Abdel Aziz Shaheen for reviewing the design and statistical analyses for this paper. We also thank Artee Karkhanis and Monica Ruff for technical and logistical help with conducting the study.
Funding: Supported by Health and Welfare Canada, Herron Foundation of Alberta, Alberta Lung Association and Conselho Nacional de Desenvolvimento Científico e Tecnológico (CNPq), Brazil. AJ is supported by the National Health and Medical Research Council of Australia.

Competing interests: None.

Ethics approval: Ethics approval was obtained from the institutional review boards at the Universities of Calgary, Alberta, Saskatchewan and Manitoba, Canada.

Provenance and peer review: Not commissioned; externally peer reviewed.

\section{REFERENCES}

1. World Health Organization. Chronic respiratory diseases. 2008. www.who.int/ respiratory/asthma/en/.

2. de Magalhaes SS, dos Santos MA, da Silva OM, et al. Inflammatory cell mapping of the respiratory tract in fatal asthma. Clin Exp Allergy 2005;35:602-11.

3. James AL, Elliot JG, Abramson MJ, et al. Time to death, airway wall inflammation and remodelling in fatal asthma. Eur Respir $J$ 2005;26:429-34.

4. James AL, Bai TR, Mauad $T$, et al. Airway smooth muscle thickness in asthma is related to severity but not duration of asthma. Eur Respir J 2009;34:1040-5.

5. Takizawa T, Thurlbeck WM. Muscle and mucous gland size in the major bronchi of patients with chronic bronchitis, asthma, and asthmatic bronchitis. Am Rev Respir Dis 1971;104:331-6.

6. Rubin BK, Tomkiewicz R, Fahy JV, et al. Histopathology of fatal asthma: drowning in mucus. Pediatr Pulmonol 2001;(Suppl 23):88-9.

7. Kuyper LM, Pare PD, Hogg JC, et al. Characterization of airway plugging in fatal asthma. Am J Med 2003:115:6-11.

8. Rubin BK. Physiology of airway mucus clearance. Respir Care 2002;47:761-8.

9. Groneberg DA, Eynott PR, Lim S, et al. Expression of respiratory mucins in fatal status asthmaticus and mild asthma. Histopathology 2002;40:367-73.

10. Deugnier MA, Teuliere J, Faraldo MM, et al. The importance of being a myoepithelial cell. Breast Cancer Res 2002:4:224-30.

11. Hasegawa M, Hagiwara S, Sato T, et al. CD109, a new marker for myoepithelial cells of mammary, salivary, and lacrimal glands and prostate basal cells. Pathol Int 2007:57:245-50

12. Li HH, Zhou G, Fu XB, et al. Antigen expression of human eccrine sweat glands. $J$ Cutan Pathol 2009;36:318-24.

13. Meyrick B, Reid L. Ultrastructure of cells in the human bronchial submucosal glands J Anat 1970;107:281-99.

14. Shimura S, Sasaki T, Sasaki H, et al. Contractility of isolated single submucosal gland from trachea. J Appl Physiol 1986;60:1237-47. 
15. Lung MA. Autonomic nervous control of myoepithelial cells and secretion in submandibular gland of anaesthetized dogs. J Physiol 2003;546:837-50.

16. Hessel PA, Mitchell I, Tough S, et al. Risk factors for death from asthma. Prairie Provinces Asthma Study Group. Ann Allergy Asthma Immunol 1999;83:362-8.

17. Global Initiative for Asthma (GINA). Global strategy for asthma management and prevention. GINA, 2007.

18. James AL, Green FH, Abramson MJ, et al. Airway basement membrane perimeter distensibility and airway smooth muscle area in asthma. J Appl Physiol 2008;104:1703-8.

19. Mauad T, Ferreira DS, Costa MB, et al. Characterization of autopsy-proven fatal asthma patients in Sao Paulo, Brazil. Rev Panam Salud Publica 2008;23:418-23.

20. Sheehan JK, Richardson PS, Fung DC, et al. Analysis of respiratory mucus glycoproteins in asthma: a detailed study from a patient who died in status asthmaticus. Am J Respir Cell Mol Biol 1995;13:748-56.

21. Cluroe A, Holloway L, Thomson K, et al. Bronchial gland duct ectasia in fatal bronchial asthma: association with interstitial emphysema. J Clin Pathol 1989;42:1026-31.

22. Benayoun L, Druilhe A, Dombret MC, et al. Airway structural alterations selectively associated with severe asthma. Am J Respir Crit Care Med 2003;167:1360-8.

23. Sanchez-Mora N, Rendon-Henao J, Monroy V, et al. Antigenic profile of human bronchial gland. Histol Histopathol 2005;20:865-70.

24. Sato K. Pharmacological responsiveness of the myoepithelium of the isolated human axillary apocrine sweat gland. Br J Dermatol 1980;103:235-43.

25. Inglis SK, Corboz MR, Taylor AE, et al. In situ visualization of bronchial submucosal glands and their secretory response to acetylcholine. Am J Physiol 1997;272:L203-10.
26. Springer J, Groneberg DA, Pregla R, et al. Inflammatory cells as source of tachykinin-induced mucus secretion in chronic bronchitis. Regul Pept 2005; 124:195-201

27. Ballard ST, Spadafora D. Fluid secretion by submucosal glands of the tracheobronchial airways. Respir Physiol Neurobiol 2007;159:271-7.

28. Carroll NG, Mutavdzic S, James AL. Increased mast cells and neutrophils in submucosal mucous glands and mucus plugging in patients with asthma. Thorax 2002;57:677-82.

29. Gailit J, Marchese MJ, Kew RR, et al. The differentiation and function of myofibroblasts is regulated by mast cell mediators. J Invest Dermatol 2001:117:1113-9.

30. Gosens R, Dueck G, Rector E, et al. Cooperative regulation of GSK-3 by muscarinic and PDGF receptors is associated with airway myocyte proliferation. Am J Physiol Lung Cell Mol Physiol 2007;293:L1348-58.

31. Gosens R, Zaagsma J, Meurs $\mathrm{H}$, et al. Muscarinic receptor signaling in the pathophysiology of asthma and COPD. Respir Res 2006;7:73.

32. James A, Carroll N. Theoretic effects of mucus gland discharge on airway resistance in asthma. Chest 1995;107:110S.

33. Chalmers GW, MacLeod KJ, Thomson L, et al. Smoking and airway inflammation in patients with mild asthma. Chest 2001;120:1917-22.

34. Schultz HD, Davis B, Coleridge HM, et al. Cigarette smoke in lungs evokes reflex increase in tracheal submucosal gland secretion in dogs. J Appl Physiol 1991;71:900-9.

35. Lewis DJ, Jakins PR. Effect of tobacco smoke exposure on rat tracheal submucosal glands: an ultrastructural study. Thorax 1981;36:622-4.

\section{Lung alert}

\section{Clinical characteristics of the H1N1 virus}

Prior to 2005, human infections with classic swine influenza viruses were reported at a rate of only one or two cases per year. However, by the late 1990s multiple strains and subtypes (H1N1, $\mathrm{H} 3 \mathrm{~N} 2$ and $\mathrm{H} 1 \mathrm{~N} 2)$ of triple-reassortant swine influenza $\mathrm{A}(\mathrm{H} 1)$ viruses containing genes from avian, human and swine influenza viruses had emerged and became enzootic among pig herds in North America.

In the first study, 11 sporadic cases of human infections with triple-reassortant swine influenza A (H1) occurring between December 2005 through February 2009 are described using information collected by the Centre for Disease Control in the USA. All but one of the cases definitely had exposure to pigs. Four patients had underlying medical conditions and the median age of the 11 infected was only 10 years. Symptoms included fever, cough, headache, sore throat, diarrhoea and myalgia. All patients recovered.

In the second study, between 15 April and 5 May 2009, a further 642 confirmed cases of H1N1 are described from 41 states in the USA. In this paper the age range is much broader ( 3 moths to 81 years). However, the symptom profile is very similar and the spectrum of disease severity ranges from mild self-limiting illness to hospitalisation and death.

Both the studies provide a description of symptoms and outcomes of this evolving virus and emphasise the importance of communication and collaboration worldwide to better understand the disease. It is possible that H1N1 infection in humans presents the greatest pandemic threat since the emergence of influenza A (H3N2) virus in 1968. The continued identification of new cases worldwide indicates sustained human to human transmission with great epidemic and pandemic threat to global public health.

- Shinde V, Bridges CB, Uyeki TM, et al. Triple-reassortant swine influenza A (H1) in humans in the United States, 2005-2009. N Engl $J$ Med 2009;360:2616-25.

- Novel Swine-Origin Influenza A (H1N1) Virus Investigation Team. Emergence of novel swine-origin influenza A (H1N1) virus in humans. N Engl J Med 2009;360:2605-15.

\section{S A Abbas}

Correspondence to: Dr S A Abbas, Specialist Registrar, Llandough University Hospital, Vale of Glamorgan, UK; ali.abbas@ doctors.org.uk

Thorax 2010;65:38. doi:10.1136/thx.2009.127399 